\title{
An Enhanced Variant Designed From DLP4 Cationic Peptide Against Staphylococcus aureus CVCC 546
}

\author{
Bing $\mathrm{Li}^{1,2+}$, Na Yang ${ }^{1,2 \dagger}$, Xiumin Wang ${ }^{1,2}$, Ya Hao ${ }^{1,2}$, Ruoyu Mao ${ }^{1,2 *}$, Zhanzhan $\mathrm{Li}^{1,2}$, \\ Zhenlong Wang ${ }^{1,2}$, Da Teng ${ }^{1,2 *}$ and Jianhua Wang ${ }^{1,2 *}$ \\ ${ }^{1}$ Gene Engineering Laboratory, Feed Research Institute, Chinese Academy of Agricultural Sciences, Beijing, China, ${ }^{2}$ Key \\ Laboratory for Feed Biotechnology, Ministry of Agriculture and Rural Affairs, Beijing, China
}

\section{OPEN ACCESS}

Edited by:

Jack Wong,

The Chinese University of Hong Kong,

China

Reviewed by:

Thanh Kha Phan,

La Trobe University, Australia

César de la Fuente,

University of Pennsylvania,

United States

${ }^{*}$ Correspondence:

Ruoyu Mao

maoruoyu@caas.cn

Da Teng

tengda@caas.cn

Jianhua Wang

wangjianhua@caas.cn;

2681298635@qq.com

${ }^{\dagger}$ These authors have contributed equally to this work

Specialty section:

This article was submitted to Antimicrobials, Resistance

and Chemotherapy,

a section of the journa

Frontiers in Microbiology

Received: 12 November 2019 Accepted: 29 April 2020

Published: 05 June 2020

Citation:

Li B, Yang N, Wang X, Hao Y, Mao R, Li Z, Wang Z, Teng $D$ and Wang J (2020) An Enhanced Variant

Designed From DLP4 Cationic

Peptide Against Staphylococcus aureus CVCC 546.

Front. Microbiol. 11:1057. doi: 10.3389/fmicb.2020.01057
Insect defensins are promising candidates for the development of potent antimicrobials against antibiotic-resistant Staphylococcus aureus (S. aureus). An insect defensin, DLP4, isolated from the hemolymph of Hermetia illucens larvae, showed low antimicrobial activity against Gram-positive $\left(\mathrm{G}^{+}\right)$pathogens and high cytotoxicity, which limited its effective therapeutic application. To obtain more potent and low cytotoxicity molecules, a series of peptides was designed based on the DLP4 template by changing the conservative site, secondary structure, charge, or hydrophobicity. Among them, a variant designated as ID13 exhibited strong antibacterial activity at low MIC values of 4 $8 \mu \mathrm{g} / \mathrm{mL}$ to $\mathrm{G}^{+}$pathogens (S. aureus: $4 \mu \mathrm{g} / \mathrm{mL}$; Staphylococcus epidermidis: $8 \mu \mathrm{g} / \mathrm{mL}$; Streptococcus pneumoniae: $4 \mu \mathrm{g} / \mathrm{mL}$; Streptococcus suis: $4 \mu \mathrm{g} / \mathrm{mL}$ ), which were lower than those of DLP4 (S. aureus: $16 \mu \mathrm{g} / \mathrm{mL}$; S. epidermidis: $64 \mu \mathrm{g} / \mathrm{mL}$; S. pneumoniae: $32 \mu \mathrm{g} / \mathrm{mL}$; S. suis: $16 \mu \mathrm{g} / \mathrm{mL})$, and cytotoxicity of ID13 (71.4\% viability) was less than that of DLP4 (63.8\% viability). ID13 could penetrate and destroy the cell membrane of $S$. aureus CVCC 546, resulting in an increase in potassium ion leakage; it bound to genomic DNA (gDNA) and led to the change of gDNA conformation. After treatment with ID13, perforated, wrinkled, and collapsed S. aureus CVCC 546 cells were observed in electron microscopy. Additionally, ID13 killed over 99.99\% of $S$. aureus within $1 \mathrm{~h}$, $2 \times \mathrm{MIC}$ of ID13 induced a post-antibiotic effect (PAE) of $12.78 \pm 0.28 \mathrm{~h}$, and $10 \mathrm{mg} / \mathrm{kg}$ ID13 caused a $1.8 \log _{10}$ (CFU/g) (CFU: colony-forming units) reduction of $S$. aureus in infected mouse thigh muscles and a downregulation of TNF- $\alpha, I L-6$, and IL-10 levels, which were superior to those of DLP4 or vancomycin. These findings indicate that ID13 may be a promising peptide antimicrobial agent for therapeutic application.

Keywords: insect defensin, peptide design, bioavailability, Staphylococcus aureus, antimicrobial mechanism, pharmacodynamics

\section{INTRODUCTION}

Antibiotics play pivotal roles in disease prevention, growth promotion, and production improvement in animal husbandry (Ferber, 2002; Cheng et al., 2014; Van Boeckel et al., 2015). Nevertheless, the long-term use of antibiotics in animal breeding can accelerate the emergence of antibiotic-resistant bacteria (ARB), including Staphylococcus aureus, which can cause trauma infection, abscess, cellulitis, mastitis, endometritis, arthritis, septicemia, and sepsis in animals 
(Fluit, 2012; Foster, 2012; Dan et al., 2019). It has been found that S. aureus is resistant to tetracycline, methicillin, erythromycin, clindamycin, ciprofloxacin, and vancomycin (Hiramatsu, 2001; Lai et al., 2018; Pirolo et al., 2019). The interactions among animals, humans, and the environment have also strengthened the spreading of ARB (Cheng et al., 2013; Laxminarayan et al., 2013; Maertens et al., 2019). These factors not only affect the effectiveness of prevention and treatment of animal diseases but also may endanger public safety (Coyne et al., 2016, 2019). Therefore, alternatives to antibiotics have become the spotlights of research in recent years (Lammie and Hughes, 2016; Moravej et al., 2018a).

Antimicrobial peptides (AMPs) are currently under evaluation as an alternative to antibiotics (Wang et al., 2016; da Cunha et al., 2017; Kang et al., 2017). AMPs have been identified in a variety of organisms (Zhang and Gallo, 2016; Bechinger and Gorr, 2017), including insects, the largest population of living organisms on earth, which have great potential as a source of AMPs (Yi et al., 2014; Koehbach, 2017). Within insects, such a class of disulfide-rich peptides is referred to as "insect defensins" most of them consisted of about 40 amino acid (AA) residues, with an N-terminal loop, an $\alpha$-helix, and an anti-parallel $\beta$-sheet cross-linked by three disulfide bonds $(\mathrm{CS} \alpha \beta)$ (Cornet et al., 1995; Landon et al., 2008) and they have broad-spectrum activity against various Gram-positive bacteria, including methicillin-resistant S. aureus (MRSA) (Józefiak and Engberg, 2017). However, most of these peptides have modest antibacterial activity and cytotoxicity, which limit their active implementation in medicine (Barreto-Santamaria et al., 2019). Based on the key $\mathrm{CS} \alpha \beta$ scaffold, a few defensins such as tenecin 1, Def-AcAA, and plectasin have been designed with an improved activity and reduced cytotoxicity (Ahn et al., 2006; Landon et al., 2008; Zhang et al., 2014). Although both academia and startups are continuing their efforts, there are still few AMP-based antibiotics in use (Roncevic et al., 2019).

In our previous study, an insect defensin, DLP4, isolated from the hemolymph of Hermetia illucens larvae (Park et al., 2015) showed a sequence identity ranging from 46.5 to $72.5 \%$ with the homologous sequences in the NCBI database. It displayed antibacterial activity against $S$. aureus and proved to be failed to induce resistance ( $\mathrm{Li}$ et al., 2017). However, the low antibacterial activity $(16 \sim 64 \mu \mathrm{g} / \mathrm{mL})$ and relatively high cytotoxicity of DLP4 limit its effective application. In the study, to improve the antibacterial activity and reduce cytotoxicity of DLP4, a series of derivatives were generated by means of AA mutations in the native sequence (Der Torossian Torres and de la Fuente-Nunez, 2019). In addition, bioavailability, antimicrobial mechanism, and pharmacodynamics were studied in vitro and in a mouse thigh model infected with S. aureus.

\section{MATERIALS AND METHODS}

\section{Bacterial Strains and Cell Lines}

The bacterial strains S. aureus ATCC 43300, Staphylococcus epidermidis ATCC 12228, and Escherichia coli ATCC 25922 were purchased from American Type Culture Collection (ATCC).
S. aureus CVCC 546, Streptococcus pneumoniae CVCC 2350, Streptococcus suis CVCC 3928, Salmonella pullorum CVCC 533, Salmonella enteritidis CVCC 3377, and E. coli K88 were purchased from the China Veterinary Culture Collection Center (CVCC). RAW 264.7 murine macrophages were obtained from Peking Union Medical College.

\section{Reagents}

Mueller-Hinton broth (MHB) and Mueller-Hinton agar (MHA) were obtained from BEIJING AOBOXING BIO-TECH CO., LTD (China). Sodium dodecyl sulfate (SDS), 3-(4,5-dimethylthiazol2-yl)-2,5-diphenyltetrazolium bromide (MTT), trifluoroethanol (TFE), and propidium iodide (PI) were purchased from SigmaAldrich (China). Dulbecco's modified Eagle medium (DMEM) and fetal bovine serum (FBS) were obtained from Gibco (China).

\section{Peptide Design, Expression, and Purification}

To develop derivatives of peptide DLP4 with improved efficacy and to study the structure-activity relationship of DLP4, we analyzed sequences containing only six conserved cysteine residues in mature defensins retrieved from Antimicrobial Peptide Database (APD) ${ }^{1}$ and used MUSCLE 3.8 for multiple sequence alignment (Figure 1). Then, a series of derivatives were generated by AA substitution based on the template of parent peptide DLP4.

Recombinant plasmids were constructed by cloning the DLP4 and its analogs encoding sequence into the $\mathrm{pPICZ} \alpha \mathrm{A}$ vector and transformed into Pichia pastoris X-33 for expression. Peptide purification was carried out with the AKTAxpress system. The purified peptides were characterized by tricine-sodium dodecyl sulfate polyacrylamide gel electrophoresis (TricineSDS-PAGE) and matrix-assisted laser desorption/ionization time-of-flight/time-of-flight tandem mass spectrometer (MALDI-TOF/TOF MS) (Ultraflextreme, Bruker, Germany) (Zhang et al., 2015).

\section{Structure Determination of Peptides Determination of Disulfide Bonds}

The S-S bonds in peptides were characterized through thermolysin enzymolysis followed by MALDI-TOF/TOF MS characterization (Lee et al., 2014). Simply, peptides were digested with thermolysin (Promega, United States) at the peptide/thermolysin ratio of 10:1 (w/w) in $100 \mathrm{mM}$ ammonium acetate, $2 \mathrm{mM} \mathrm{CaCl}_{2}(\mathrm{pH} 6.2)$ at $60^{\circ} \mathrm{C}$ for $1 \mathrm{~h}$, after which the hydrolysates were separated by RP-HPLC, and characterized by MALDI-TOF/TOF MS (Ultraflextreme, Bruker, Germany).

\section{Circular Dichroism (CD) of Peptides}

The secondary structure of AMPs can be determined by CD on a Bio-Logic MOS-450 spectropolarimeter (France). CD measurements of peptides were performed in $\mathrm{ddH}_{2} \mathrm{O}, 40 \mathrm{mM}$ SDS, or $50 \%$ TFE using a $1.0-\mathrm{mm}$ path-length cuvette; the spectra were recorded from 180 to $260 \mathrm{~nm}$ at room temperature three times (Lin et al., 2018).

\footnotetext{
${ }^{1}$ http://aps.unmc.edu/AP
} 

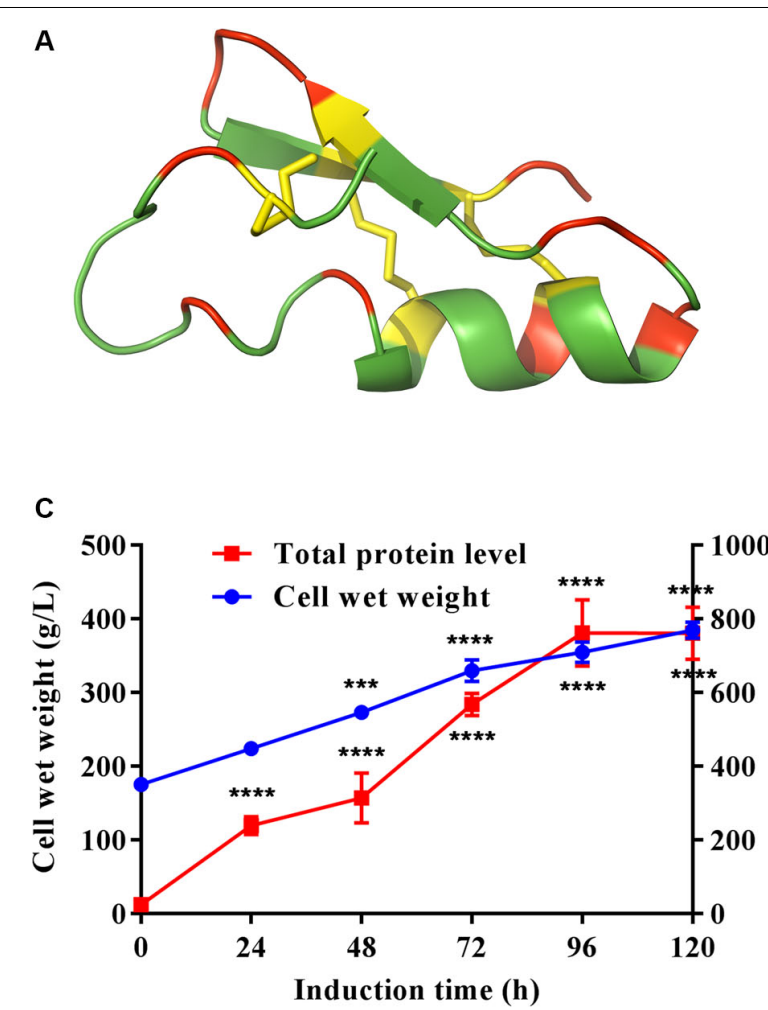

B

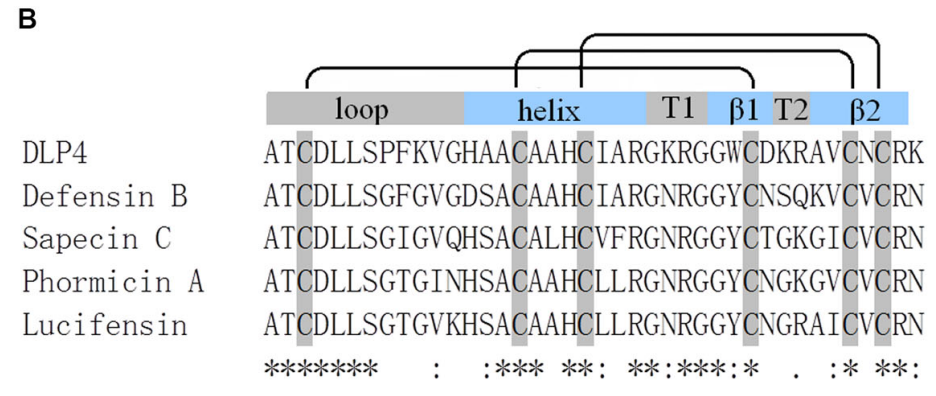

FIGURE 1 | (A) Representation of the 3D structure of DLP4 was built from Def-AcAA (PDB: 2nz3). Yellow, red, and green represent cysteines and disulfide bonds and charged and neutrally charged residues, respectively. (B) Multiple alignments of the insect defensins derived from APD were carried out using MUSCLE 3.8. The boxes above the alignment represent loop, helix, turns, and $\beta$ strands, respectively. The black lines indicate the disulfide bond between cysteines. The "*” under the sequences indicates positions which have a single, fully conserved residue, the ":" indicates conservation between groups of strongly similar properties, and the "." indicates conservation between groups of weakly similar properties. (C) Time curves of the total protein levels and cell wet weights. Total protein and biomass are measured every $24 \mathrm{~h}$. Statistical significance of differences between 24 to $120 \mathrm{~h}$ and $0 \mathrm{~h}$ was determined using the two-way ANOVA and Dunnett's multiple comparisons. ${ }^{\star \star \star} p<0.001 ;{ }^{\star \star \star \star} p<0.0001$. (D) Tricine-SDS-PAGE and MALDI-TOF MS analysis of the purified ID13. M: ultra-low molecular weight protein marker; lane 1: purified ID13.

\section{Bioavailability Analyses Antimicrobial Activity}

The minimal inhibitory concentration (MIC) was evaluated by a microtiter plate assay (Wiegand et al., 2008). Serial 2fold dilutions of test peptides were placed into a 96-well plate containing identical bacterial inoculum and incubated at $37^{\circ} \mathrm{C}$ for $16 \sim 20 \mathrm{~h}$. Vancomycin was used as antibiotic control. The MIC value was defined as the lowest peptide concentration where no visible growth occurred. All tests were made in triplicate.

\section{Hemolysis}

Hemolytic activity of peptides was evaluated with fresh mouse erythrocytes. Briefly, fresh mouse erythrocytes were collected, washed, and resuspended to a concentration of $8 \%(\mathrm{v} / \mathrm{v})$ in PBS. Then, an aliquot of erythrocyte solution was added to 96-well plates containing an equal volume of peptide solution $(1 \sim 256 \mu \mathrm{g} / \mathrm{mL})$ and was incubated for $1 \mathrm{~h}$ at $37^{\circ} \mathrm{C}$. The erythrocyte suspension treated with $0.1 \%$ Triton X-100 and left untreated was employed as positive and negative controls, respectively. After centrifugation at $2000 \mathrm{rpm}$ for $5 \mathrm{~min}$, the supernatant was measured using a microplate reader at $576 \mathrm{~nm}$. The percent hemolysis was calculated using the following formula: Percent hemolysis = $\left[\left(A-A_{0}\right) /\left(A_{100}-A_{0}\right)\right] \times 100 \%$, where $A, A_{100}$, and $A_{0}$ represent the absorbance of the peptide sample and positive and negative controls, respectively.

\section{Mammalian Cytotoxicity}

The cytotoxicity of peptides toward mouse macrophage RAW 264.7 was evaluated by the MTT assay as described previously (Wang X. et al., 2018).

\section{Antimicrobial Mechanism of Peptides Effects of Peptides on S. aureus Membrane Membrane permeabilization}

The effects of peptides on membrane permeabilization were measured by flow cytometry (Zhu et al., 2018). Briefly, S. aureus CVCC 546 cells in the exponential phase $\left(10^{8} \mathrm{CFU} / \mathrm{mL}, \mathrm{CFU}\right.$ : colony-forming units) were treated with peptides at $1 \times, 2 \times$, or $4 \times \mathrm{MIC}$ and incubated with $50 \mu \mathrm{L}$ PI at $0.5 \mathrm{mg} / \mathrm{mL}$ for $30 \mathrm{~min}$ at $25^{\circ} \mathrm{C}$. Cells untreated and treated with $2 \times \mathrm{MIC}$ DLP4 or vancomycin were used as blank and positive controls. The fluorescence of the dye was monitored at an excitation wavelength of $488 \mathrm{~nm}$ and an emission wavelength of $635 \mathrm{~nm}$. 


\section{Potassium ion $\left(\mathrm{K}^{+}\right)$leakage}

To further investigate the effects of peptides on membrane integrity, $\mathrm{K}^{+}$leakage determination was carried out as previously described (Miao et al., 2016). Briefly, S. aureus CVCC 546 cells were centrifuged, washed, and resuspended in $0.9 \%$ sterile saline. The cell suspension $\left(10^{8} \mathrm{CFU} / \mathrm{mL}\right)$ was treated with peptides at $1 \times$ MIC. Cells untreated and treated with DLP4 or nisin were used as blank and positive controls. At time intervals of $30,60,90,120$, and $150 \mathrm{~min}$, the suspensions were centrifuged at $12000 \mathrm{rpm}$ for $5 \mathrm{~min}$. The supernatants were then subjected to measurement by Agilent inductively coupled plasma optical emission (ICP-OES).

\section{Effects of Peptides on S. aureus Genomic DNA Gel retardation}

A gel retardation assay (Zhao et al., 2019) was utilized to analyze the binding of peptides to genomic DNA (gDNA) extracted from S. aureus CVCC 546 with TIANamp Bacteria DNA Kit (TIANGEN Biotech Co., Ltd., Beijing). The peptides were incubated for $10 \mathrm{~min}$ with gDNA at different ratios of $0-5.0(\mathrm{w} / \mathrm{w})$ and then loaded on $1 \%$ agarose gel for electrophoresis analysis.

\section{Atomic force microscopy (AFM)}

Atomic force microscopy images of gDNA-peptide complexes were carried out as described previously (Fojan and Gurevich, 2017). Simply, gDNA $(1 \mu \mathrm{g} / \mathrm{mL})$ was incubated with equalvolume peptides $(5 \mu \mathrm{g} / \mathrm{mL})$ at $30^{\circ} \mathrm{C}$ for $10 \mathrm{~min}$. Then, the sample was scanned by multimode 8 AFM (Bruker, United States).

\section{CD spectra}

Circular dichroism measurements (Bakshi et al., 2014) were carried out to examine the effect of peptide on the secondary structure of $S$. aureus CVCC 546 gDNA at peptide/gDNA ratios of 0.5 and 1, respectively. After incubation, the mixtures were loaded and scanned from 220 to $320 \mathrm{~nm}$ at room temperature with a Bio-Logic MOS450 spectropolarimeter (France).

\section{Morphological Observations}

To further characterize the bactericidal effects of peptides, scanning electron microscopy (SEM) and transmission electron microscopy (TEM) were used to visualize the morphological changes. S. aureus CVCC 546 cells in the exponential phase $\left(10^{8}\right.$ $\mathrm{CFU} / \mathrm{mL}$ ) were treated with $4 \times \mathrm{MIC}$ peptides at $37^{\circ} \mathrm{C}$ for $2 \mathrm{~h}$ or left untreated as control. Cells for SEM or TEM were processed as described previously (Yang et al., 2019) and samples were observed using a QUANTA 200 SEM (FEI, Philips, Netherlands) or a JEM-1400 (JEDL, Tokyo, Japan).

\section{In vitro and in vivo Pharmacodynamics} Time-Kill Assay

Time-kill assay was used to assess the killing rates of $S$. aureus cells by AMPs in vitro, done by measuring the number of viable bacteria left at various times after exposure to the peptides. Simply, reagents were added to MHB medium containing $10^{5}$ $\mathrm{CFU} / \mathrm{mL}$ S. aureus CVCC 546 at the final concentrations of $1 \times, 2 \times$, or $4 \times \mathrm{MIC}$; the mixture was incubated at $37^{\circ} \mathrm{C}$ and $250 \mathrm{rpm}$. At different time intervals, a certain sample was taken, serially diluted, and plated on MHA for colonies counting. Cells treated with $2 \times$ MIC DLP4 or vancomycin and left without treatment were used as the positive and blank controls, respectively (Flamm et al., 2019).

\section{Post-antibiotic Effect (PAE)}

The PAE was determined by exposing $S$. aureus cells to antimicrobial agent at $1 \times, 2 \times$, or $4 \times$ MIC for $2 \mathrm{~h}$. After drug removal by dilution, the bacterial culture was incubated at $37^{\circ} \mathrm{C}$ and $250 \mathrm{rpm}$. An aliquot of samples $(50 \mu \mathrm{L})$ were taken for CFU counts at different time intervals until bacterial cultures became turbid. Bacteria treated with DLP4 or vancomycin and left without treatment were used as the positive and blank controls, respectively. The PAE was calculated using the following formula: $P A E=T-C$, where $T$ is the time for the CFU counts to increase by 10 -fold above the count observed immediately after drug removal, and $C$ is the corresponding time for the untreated control (Oh et al., 2019).

\section{Mouse Thigh Infection Model}

Mouse experiments were carried out at Gene Engineering Laboratory, Feed Research Institute of Chinese Academy of Agricultural Sciences (CAAS) and complied with institutional animal care and use policies and procedures (AEC-CAAS20090609). All animal studies were performed with female CD-1 mice, $6 \sim 7$ weeks old.

S. aureus CVCC 546 in the exponential phase were resuspended in $\mathrm{MHB}$ and adjusted to $1 \times 10^{8} \mathrm{CFU} / \mathrm{mL}$, a 0.1 $\mathrm{mL}$ inoculum was injected into the right thighs of mice. At $2 \mathrm{~h}$ post-infection, mice $(n=6)$ were administered intraperitoneally (i.p.) with peptides at $2.5,5$, or $10 \mathrm{mg} / \mathrm{kg}$. Mice raised without any treatment, or treated with PBS, $10 \mathrm{mg} / \mathrm{kg}$ DLP4, or vancomycin were used as the blank and negative and positive controls, respectively. At $24 \mathrm{~h}$ post-infection, peripheral blood was collected and serum was separated for cytokine levels analysis by using enzyme-linked immunosorbent assay (ELISA) kit (R\&D systems, United States). Mice were euthanized, the right thighs were aseptically removed and processed for colonies counting (Ling et al., 2015).

\section{Statistical Analysis}

All data are presented as mean \pm standard deviation (SD), where " $n$ " represents the number of animals or samples. Statistical analysis was performed by one-way or two-way analysis of variance (ANOVA) followed by Dunnett's multiple comparisons test using GraphPad Prism 7 or OriginPro 8. $p<0.05$ was considered statistically significant.

\section{RESULTS}

\section{Peptide Design and Expression}

As shown in Figures 1A,B, a multiple alignment revealed insect defensins retrieved from APD share high homology of $59 \% \sim 87.5 \%$ between the primary structures of those peptides, 
which comprise three apparent regions, an N-terminal loop, a central amphipathic $\alpha$ helix, and a C-terminal anti-parallel $\beta$-sheet. The helix is separated from the $\beta$-sheet by turn T1 and the two $\beta$-sheets by turn T2. In addition to the similar structural topology, the specifics of different insect defensins are diverse. The loop motif shows high variability, especially for DLP4, where the terminal of the loop account for its particular variability. The helix always ends with the $\mathrm{R} 23$ residue, followed by a $G$ residue which is involved in a hydrogen bond with the carbonyl group of C3 (Landon et al., 2008). Hydrophobic side chains distributed over the surface present a number of hydrophobic spots, some of which correspond to conservative AA: A1, T2, L5, L6, A15, and A17; others are more specific: P8, A14, and W29 for DLP4, I9, L18, L21, and F22 for Sapecin C; and I11 for Phormicin A. Charged residues at the end of the helix, turns $\mathrm{T} 1$ and $\mathrm{T} 2$, and the C-terminus form positive areas. Variable and conserved regions were also displayed (Figure 1B), based on these regions, peptides ID1 ID3 were designed by substituting cysteines in one pair of disulfide bonds with A residue; ID4 ID7 were changed at the conservative sites with AA of similar properties; ID8 ID26 were generated with varied charges through a basic or acidic AA replacement; ID27 ID30 were designed by changing hydrophobicity while keeping charge unchanged (Table 1 and Supplementary Table S1).

The peptides listed in Table $\mathbf{1}$ were inserted into plasmids and successfully expressed in $P$. pastoris X-33. The production of peptide ID13 was performed in a 5-L fermenter with total protein of $761 \mathrm{mg} / \mathrm{L}$ and biomass of $385 \mathrm{~g} / \mathrm{L}$ at $120 \mathrm{~h}$ by induction (Figure 1C). A molecular weight of $4197.01 \mathrm{Da}$ was shown by MALDI-TOF/TOF MS (Figure 1D), which was consistent with the theoretical molecular mass of 4197.93 Da of ID13 (Table 1).

\section{Bioavailability of ID13 Antibacterial Activity}

The MICs of DLP4 and its analogs were tested preferentially against $S$. aureus ATCC 43300, among them, peptide ID13 (with the MIC of $4 \mu \mathrm{g} / \mathrm{mL}$ ) exerted the most potent antibacterial activity against $S$. aureus ATCC 43300, and the MICs of other 29 derivatives were $8 \sim 64 \mu \mathrm{g} / \mathrm{mL}$ (Table 1). The MICs of peptide ID13 were further tested against other Gram-positive bacteria and Gram-negative bacteria. The result showed that ID13 (with MICs of $4 \sim 8 \mu \mathrm{g} / \mathrm{mL}$ ) had higher activity than DLP4 (with MICs of $16 \sim 64 \mu \mathrm{g} / \mathrm{mL}$ ) against $S$. aureus CVCC 546, S. epidermidis ATCC 12228, S. pneumoniae CVCC 2350, and S. suis CVCC 3928 (Table 2). However, similar to DLP4, ID13 had no activity against Gram-negative bacteria.

\section{Hemolysis and Cytotoxicity of Peptide ID13}

As shown in Figure 2, the hemolysis of ID13 against mouse erythrocytes was $0.38 \%$ at $128 \mu \mathrm{g} / \mathrm{mL}$, lower than that of DLP4 $(0.61 \%)$ and vancomycin $(0.54 \%)$. The cell viability of ID13 against mouse macrophages RAW 264.7 was $71.4 \%$ at $256 \mu \mathrm{g} / \mathrm{mL}$, higher than that of DLP4 (63.8\%), but lower than that of vancomycin $(85.8 \%)$. The results indicated that ID13 had lower hemolysis and cytotoxicity than DLP4.

\section{Structure Determination of Peptide ID13} Disulfide Bonds of Peptide ID13

To locate the disulfide bonds in ID13, the cysteine-containing peptide pairs were obtained by thermolytic digestion, and characterized by MALDI-TOF/TOF MS. As shown in Supplementary Figure S1, the disulfide bond-unreduced peptide fragments ATCDLLSPFK and GGWCDGR showed a $\mathrm{m} / \mathrm{z}$ of 921.4 , suggesting they were connected by Cys3 and Cys30, and VGHAACAAHCIAR and AVCNCR had a m/z of 970.45, indicating they were cross-linked by Cys 13 and Cys23, and Cys20 and Cys38. The results agreed with those predicted from the Def-AcAA (Figure 1A).

\section{CD of Peptide ID13}

The secondary structure of the peptide was measured in the presence of $\mathrm{H}_{2} \mathrm{O}, 50 \%$ TFE, or $40 \mathrm{mM}$ SDS which were used to simulate aqueous, microbial membrane and hydrophobic conditions, respectively (Tan et al., 2019). CD spectra showed peptide ID13 (Figure 3A) as well as DLP4 (Figure 3B) possessed a positive peak between 185 and $195 \mathrm{~nm}$ followed by two negative peaks at approximately 208 and $222 \mathrm{~nm}$, indicating an $\alpha \beta$ structure in all three environments. Compared with DLP4, the CD peaks of ID13 decreased in $\mathrm{H}_{2} \mathrm{O}$ and $50 \%$ TFE and increased in $40 \mathrm{mM}$ SDS. It suggested that ID13 tended to form $\alpha$-helix in microbial membrane (40 mM SDS) conditions while DLP4 was prone to form $\alpha$-helix in hydrophobic conditions (50\% TFE).

\section{Anti-S. aureus Mechanism of Peptide ID13 \\ Effects of ID13 on S. aureus Membrane Membrane permeabilization}

Propidium iodide can penetrate the damaged cell membrane and intercalate into DNA and was utilized to assess the membrane integrity of $S$. aureus CVCC 546 cells. As shown in Figure 4A, in the absence of peptides, $1.18 \%$ of the cells showed PI fluorescent signal. When treated with ID13 at $1 \times, 2 \times$, or $4 \times$ MIC for $0.5 \mathrm{~h}$, the percentage of PI-positive cells were $47.2 \%, 48.2 \%$, and $52.8 \%$, respectively. By comparison, after being treated with $2 \times \mathrm{MIC}$ DLP4 or vancomycin, the percentages of PI-positive cells were $41.8 \%$ and $5.1 \%$, respectively. It indicated that ID13 induced more potent damage to $S$. aureus CVCC 546 than its parent peptide DLP4, and the action mode of ID13 and DLP4 may be different from that of vancomycin.

\section{$K^{+}$leakage}

To further demonstrate the impacts of peptide ID13 on the cell membrane integrity of $S$. aureus CVCC 546 cells, the levels of $\mathrm{K}^{+}$ released from $S$. aureus CVCC 546 cells were determined by ICPMS. As shown in Figure 4B, in the absence of peptide ID13, the amount of extracellular $\mathrm{K}^{+}$was relatively stable at low level of $0.31 \sim 0.56 \mathrm{mg} / \mathrm{L}$. By comparison, after being treated for $150 \mathrm{~min}$, the levels of released $\mathrm{K}^{+}$from $S$. aureus CVCC 546 were up to $0.81 \mathrm{mg} / \mathrm{L}$ by ID13, $0.72 \mathrm{mg} / \mathrm{L}$ by DLP4, and $1.03 \mathrm{mg} / \mathrm{L}$ by nisin. The results suggested that the destruction of the cell membrane by ID13 is more potent than DLP4, which was consistent with the results of PI-positive cells. 
TABLE 1 | Physicochemical parameters of parental and designed peptides.

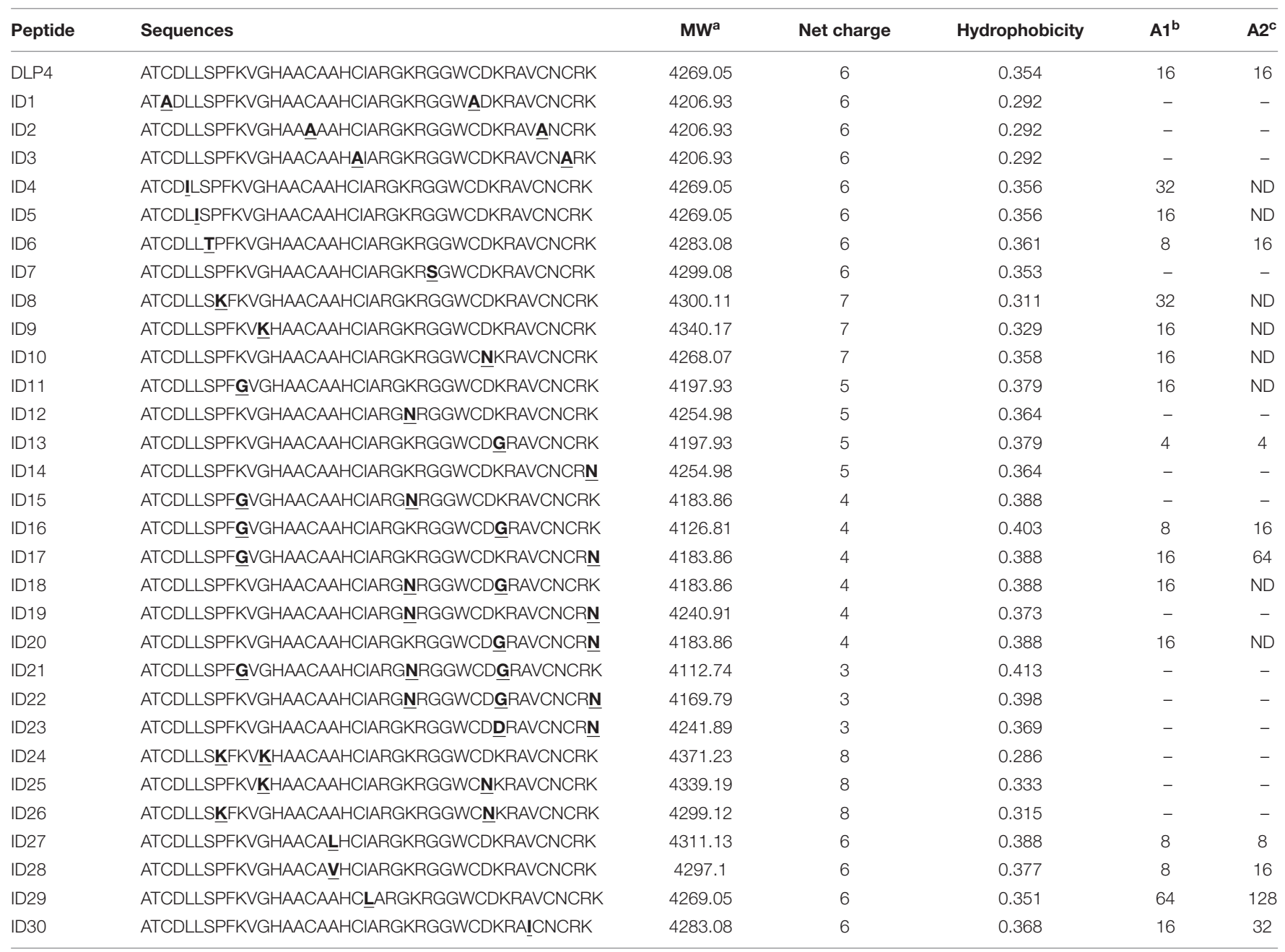

Changed amino acids are shown in bold and underlined. ${ }^{a}$ Molecular weight (Da). ${ }^{b}$ Activities (MICs, $\mu \mathrm{g} / \mathrm{mL}$ ) of peptides were tested against S. aureus ATCC 43300 ; inactive peptides are indicated by " -," tested by drop-diffusion assay. ${ }^{\circ}$ Activities (MICs, $\mu \mathrm{g} / \mathrm{mL}$ ) of peptides were tested against S. aureus CVCC 546; inactive peptides are indicated by "-," tested by drop-diffusion assay; ND: not determined.

TABLE 2 | MICs of the designed peptides against pathogenic strains.

\begin{tabular}{|c|c|c|c|c|c|c|}
\hline \multirow{3}{*}{ Species and strains } & \multicolumn{6}{|c|}{ MICs } \\
\hline & \multicolumn{2}{|c|}{ ID13 } & \multicolumn{2}{|c|}{ DLP4 } & \multicolumn{2}{|c|}{ Vancomycin } \\
\hline & $\mu \mathbf{M}$ & $\mu \mathrm{g} / \mathrm{mL}$ & $\mu \mathbf{M}$ & $\mu \mathrm{g} / \mathrm{mL}$ & $\mu \mathbf{M}$ & $\mu \mathrm{g} / \mathrm{mL}$ \\
\hline \multicolumn{7}{|l|}{ Gram-positive bacteria } \\
\hline Staphylococcus aureus CVCC 546 & 0.95 & 4 & 3.75 & 16 & 0.67 & 1 \\
\hline S. epidermidis ATCC 12228 & 1.91 & 8 & 14.99 & 64 & 0.67 & 1 \\
\hline Streptococcus pneumoniae CVCC 2350 & 0.95 & 4 & 7.50 & 32 & 0.34 & 0.5 \\
\hline S. suis CVCC 3928 & 0.95 & 4 & 3.75 & 16 & 0.17 & 0.25 \\
\hline \multicolumn{7}{|l|}{ Gram-negative bacteria } \\
\hline Escherichia coli ATCC 25922 & $>30.50$ & $>128$ & $>29.98$ & $>128$ & 86.15 & 128 \\
\hline E. coli K88 & $>30.50$ & $>128$ & $>29.98$ & $>128$ & 43.08 & 64 \\
\hline Salmonella pullorum CVCC 533 & $>30.50$ & $>128$ & $>29.98$ & $>128$ & 86.15 & 128 \\
\hline S. enteritidis CVCC 3377 & $>30.50$ & $>128$ & $>29.98$ & $>128$ & 86.15 & 128 \\
\hline
\end{tabular}



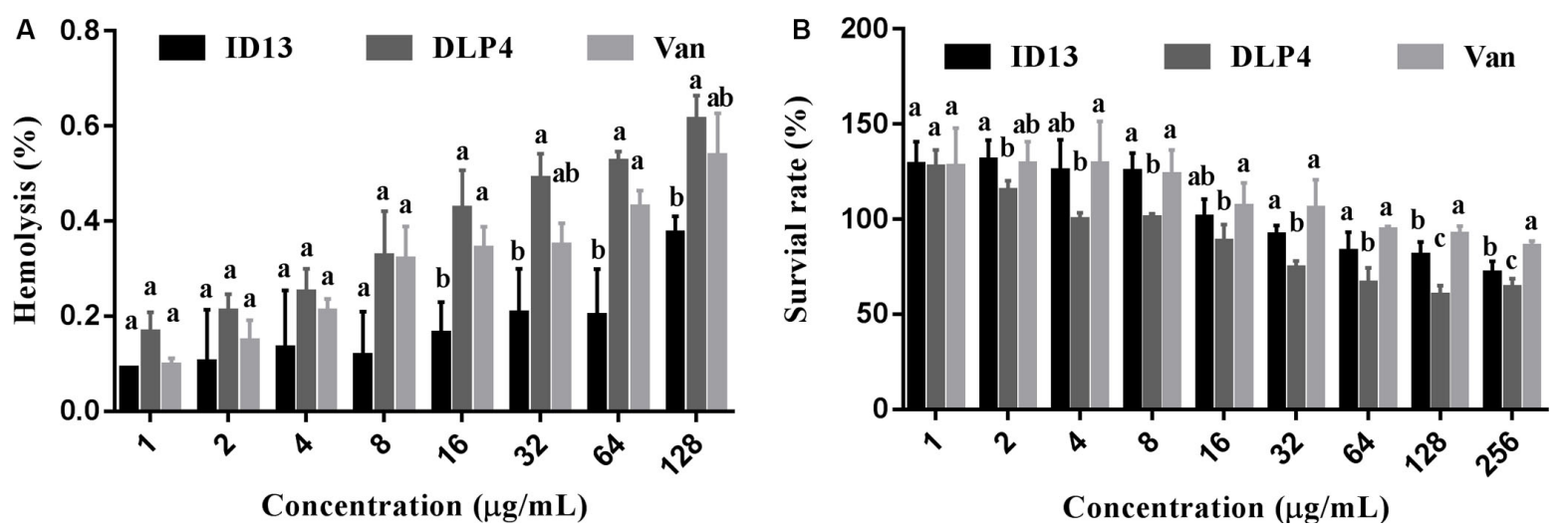

FIGURE 2 | (A) Hemolytic activities of ID13, DLP4, and vancomycin (Van) against mouse erythrocytes ( $n=3)$. (B) Cytotoxicity of ID13, DLP4, and vancomycin (Van) against RAW $264.7(n=4)$. Mean values in the same concentration with different lowercase letters indicate a significant difference $(p<0.05)$.
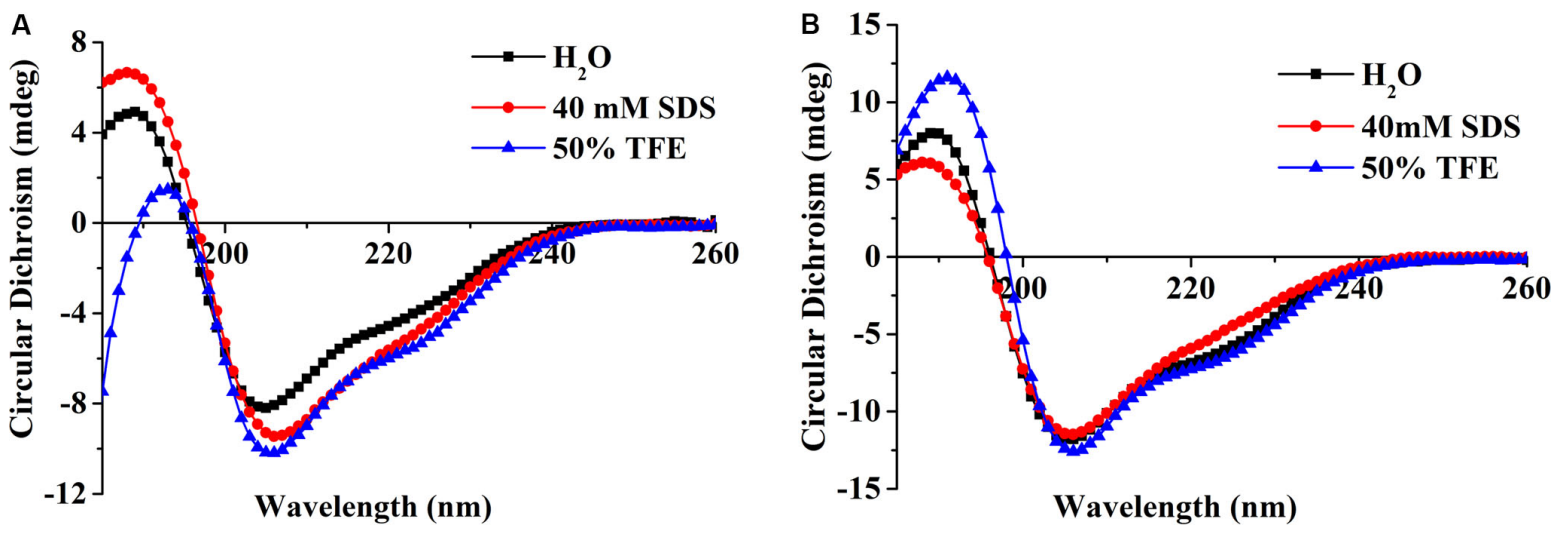

FIGURE 3 | CD spectra of the peptide ID13 (A) and DLP4 (B) in $\mathrm{H}_{2} \mathrm{O}, 40 \mathrm{mM}$ SDS, or 50\% TFE.
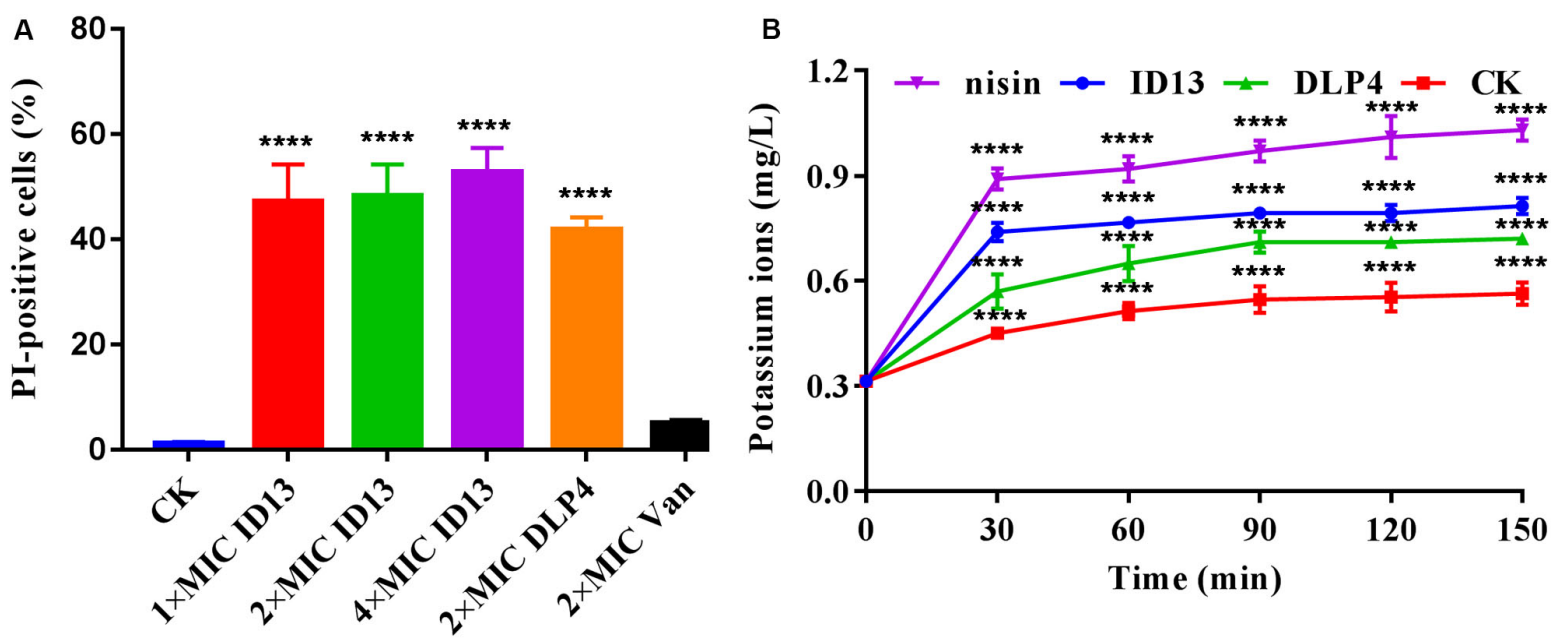

FIGURE 4 | (A) Flow cytometric analysis of S. aureus CVCC 546. Cells were treated with $1 \times, 2 \times$, or $4 \times$ MIC ID13, respectively; cells treated with $2 \times$ MIC DLP4 or vancomycin (Van) and left without treatment were used as the positive and negative control, respectively $(n=3)$. (B) The extracellular levels of $\mathrm{K}^{+}$released by S. aureus CVCC 546 cells treated with peptide ID13, DLP4, and nisin, respectively $(n=3)$. Statistical significance of differences was determined using (A) one-way and (B) two-way ANOVA followed by Dunnett's multiple comparison. ${ }^{\star \star \star \star} p<0.0001$. 


\section{Effects of ID13 on S. aureus Genomic DNA DNA binding}

To probe potential intracellular targets, the DNA gel retardation assay and AFM were performed. As shown in Figure 5A, ID13 began to retard the migration of $S$. aureus CVCC 546 gDNA at the peptide/gDNA mass ratio of 1 while DLP4 did at 0.5. The DNAbinding ability was enhanced with the increase in peptide/gDNA mass ratio. gDNA was completely blocked at ID13/gDNA of 5 and that for DLP4/gDNA at 2.5. Furthermore, the AFM images also showed that DLP4 had a stronger binding ability to gDNA than that of ID13 (Figure 5B), which may ascribe to its more net positive charges (Table 1).

\section{CD spectra}

Circular dichroism was utilized to estimate the conformation changes of bacterial gDNA caused by ID13. Native bacterial gDNA presents a $\mathrm{B}$ conformation, which provides a conservative CD spectrum with a positive band around $270 \mathrm{~nm}$ and a negative one around $245 \mathrm{~nm}$ (Yao et al., 2018). When exposed to ID13, precipitation in gDNA was observed, the positive band at $270 \mathrm{~nm}$ decreased and the negative one at $245 \mathrm{~nm}$ gradually disappeared. In contrast, the CD band of DLP4-treated gDNA showed more intense changes (Figure 5C), which may attribute to its increased charge. It indicated that ID13 as well DLP4 can interact with gDNA and destruct its structure.

\section{Morphological Characterization}

The microscopic morphology and ultrastructure changes of S. aureus CVCC 546 were observed by SEM and TEM. As shown in Figure 6A, compared with the intact control group, the cell surface of peptide ID13-treated S. aureus CVCC 546 was significantly changed, with evident cell envelope perforation and deformation. TEM image showed a complete microscopic surface and a dense internal structure of $S$. aureus CVCC 546 cells in the control. In contrast, ID13 significantly damaged S. aureus CVCC 546 ultrastructure, including the rupture of cell envelope, the release of intracellular contents, the formation of mesosomelike structure and empty regions, and complete lysis of the cells. Compared to ID13, it seemed DLP4 caused less damage to S. aureus CVCC 546 (Figure 6B). Furthermore, there were no obvious morphological changes in the $4 \times$ MIC vancomycintreated S. aureus CVCC 546 cells (Figure 6), indicating different action modes between peptides ID13, DLP4, and vancomycin.

\section{Pharmacodynamics of Peptide ID13}

Based on the attractive mode in which peptide ID13 acts, we investigated its potential as a therapeutic drug through time-kill assay, PAE, and mouse thigh infection model.

\section{Time-Kill Assay}

As shown in Figure 7A, after being treated with $1 \times, 2 \times$, or $4 \times$ MIC ID13, the CFU counts of $S$. aureus CVCC 546 decreased within $1 \mathrm{~h}$ by $2.16,3.14$, and $3.4 \log _{10} \mathrm{CFU} / \mathrm{mL}$, respectively, equivalent to a CFU reduction of more than $99.99 \%$. In contrast, for $2 \times$ MIC DLP4 or vancomycin, there was a reduction of $2.7 \log _{10} \mathrm{CFU} / \mathrm{mL}$ and $0.22 \log _{10} \mathrm{CFU} / \mathrm{mL}$, respectively. The results suggested that ID13 had more potent bactericidal activity against S. aureus CVCC 546 cells than did DLP4 and vancomycin. Furthermore, the regrowth of bacterial cells was observed after being treated with $2 \times$ MIC vancomycin in the post-incubation time. Note that the common clinical failure of vancomycin in the treatment of $S$. aureus may relate to its the poor bactericidal activity (Sakoulas et al., 2004; Kollef, 2007).

\section{PAE}

Post-antibiotic effect is an important indicator of medication frequency (Zhanel and Craig, 1994). ID13 produced a longer PAE $(12.78 \pm 0.28 \mathrm{~h})$ against $S$. aureus CVCC 546 than that of DLP4 $(8.20 \pm 0.19 \mathrm{~h})$ and vancomycin $(1.36 \pm 0.20 \mathrm{~h})$ at $2 \times$ MIC. Increasing the concentrations of ID13 significantly prolonged its duration of PAE (Figure 7B).

\section{Mouse Thigh Infection Model}

The in vivo efficacy was then performed in a mouse thigh infection model. At $2 \mathrm{~h}$ post-infection with $S$. aureus CVCC 546, ID13 was administered i.p. at single doses ranging from 2.5 to $10 \mathrm{mg} / \mathrm{kg}$. The result showed that ID13 generated a 1.8 $\log _{10}(\mathrm{CFU} / \mathrm{g})$ reduction in infected thigh muscles at $10 \mathrm{mg} / \mathrm{kg}$, superior to DLP4 with $1.7 \log _{10}(\mathrm{CFU} / \mathrm{g})$ and vancomycin with $0.77 \log _{10}(\mathrm{CFU} / \mathrm{g}$ ) (Figure 7C). Moreover, it observed a significant downregulation of serum levels of TNF- $\alpha$, IL-6, and IL-10 by $1123.30 \mathrm{pg} / \mathrm{mL}, 750.02 \mathrm{pg} / \mathrm{mL}$, and $37.66 \mathrm{pg} / \mathrm{mL}$, respectively, superior to DLP4 (TNF- $\alpha$ : $1103.30 \mathrm{pg} / \mathrm{mL}$, IL-6: $710.02 \mathrm{pg} / \mathrm{mL}$, and IL-10: $29.06 \mathrm{pg} / \mathrm{mL}$ ) and vancomycin (TNF- $\alpha$ : $1052.98 \mathrm{pg} / \mathrm{mL}, \mathrm{IL}-6: 497.48 \mathrm{pg} / \mathrm{mL}$, and IL-10: $15.82 \mathrm{pg} / \mathrm{mL}$ ) at the same concentration $(10 \mathrm{mg} / \mathrm{kg})$ (Figures $7 D-F)$.

\section{DISCUSSION}

Staphylococcus aureus is disreputable for its potential to get resistance to antibiotics, attracting attention to novel antimicrobial strategies (Chambers and Deleo, 2009; Wenzel et al., 2014). The clinical development of AMPs is currently under evaluation. However, most of these AMPs have low antimicrobial activity and relatively high cytotoxicity (Fjell et al., 2011; Kubicek-Sutherland et al., 2017; Barreto-Santamaria et al., 2019), which limit their therapeutic application[15]. Insect defensins are a group of evolutionarily conserved AMPs with a length distribution between 32 and 52 residues and charges vary from -5 to +8 . They share a common $\operatorname{CS} \alpha \beta$ motif, which have been proved to be valuable structural templates in peptide engineering (Koehbach, 2017). In this work, a naturally occurring sequence DLP4 was used as a template to design more potent and low toxic molecules.

In general, bioactivity of AMPs is strongly associated with their structures; especially the presence of intramolecular disulfide bonds is critical for their conformation and bioactivity (Koehbach, 2017). In our work, peptides ID1-ID3 (with one pair of disulfide bonds blocked by alanine) presented no activity in a drop-diffusion assay (Table 1). Similar results have also been reported for lucifensin and coprisin (Cerovsky et al., 2011; Lee et al., 2014). Studies have shown that truncated defensins at the N-terminal caused decreased antimicrobial 

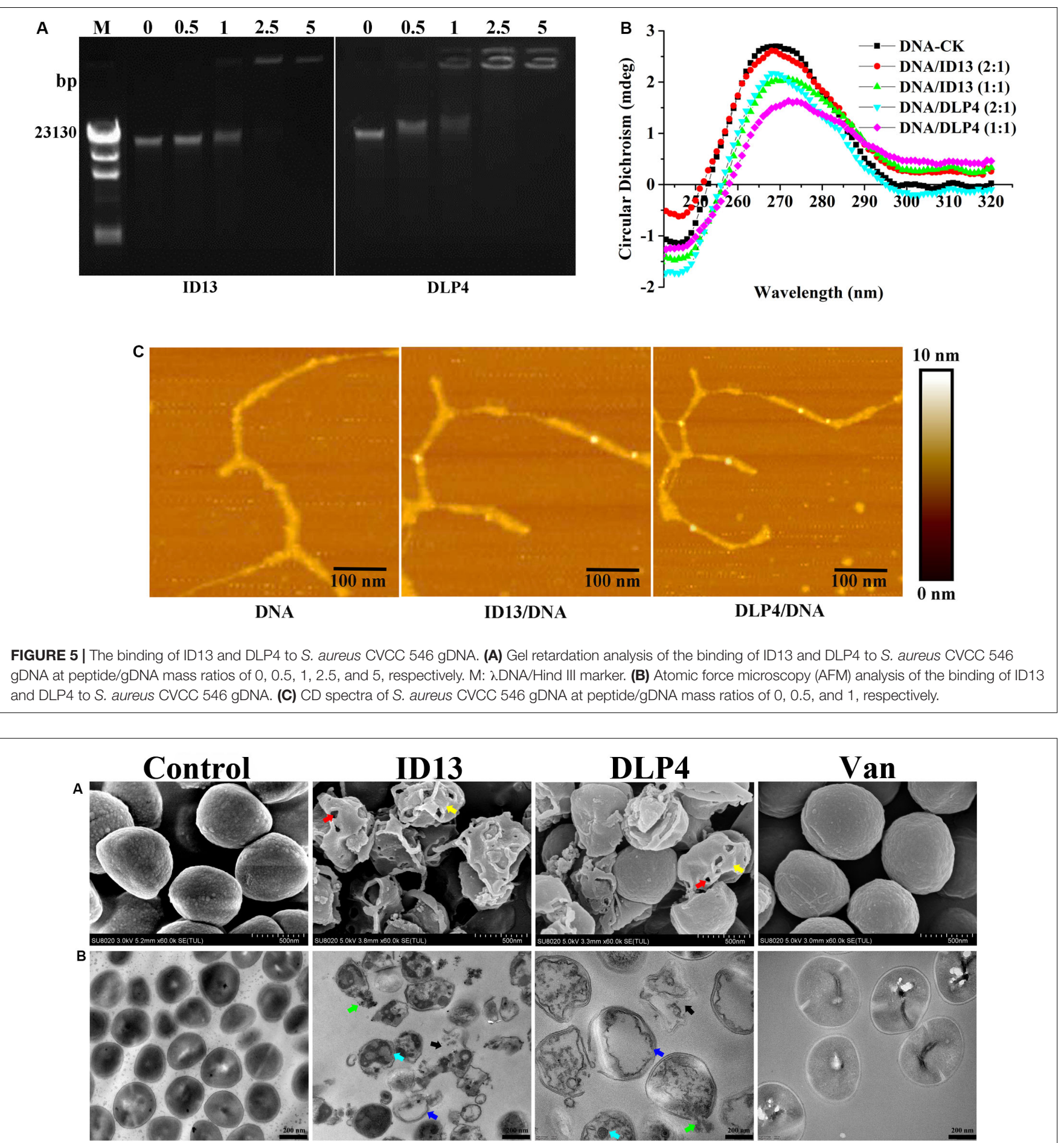

FIGURE 6 | (A) SEM and (B) TEM micrographs of S. aureus CVCC 546 treated with ID13, DLP4, or vancomycin (Van) at $4 \times$ MIC for $2 \mathrm{~h}$ or left untreated as control. Red arrow: membrane perforation; yellow arrow: cell shrinkage; green arrow: leakage of cytosol; blue arrow: empty regions; cyan arrow: mesosome-like structure; black arrow: cell rupture.

activity (Lee et al., 1998; Cerovsky et al., 2011), yet fail to identify single residues that are responsible and highlighting the complexity of sequence-based approaches. In our study, single-conserved AA mutation L5I, L6I, and S7T (with ID4,
ID5, and ID6, respectively) in the N-terminal loop had no significant effect on the antibacterial activity. However, the mutant ID7 (with G27S) showed no antibacterial activity, which may be due to the effect of hydroxyl groups of $S$ residues 

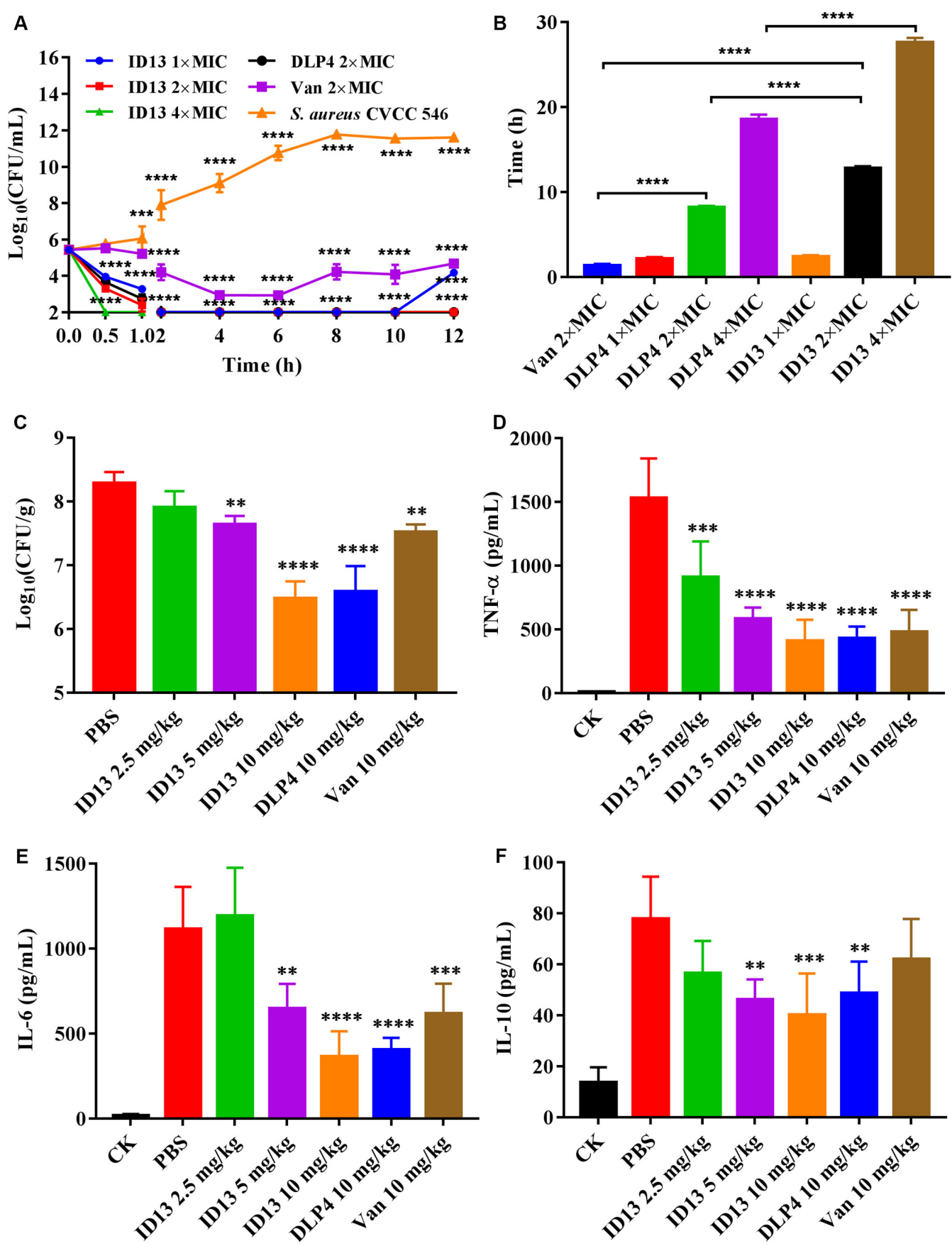

FIGURE 7 | The efficacy of peptide ID13 in vitro and in vivo with DLP4 and vancomycin (Van) as positive controls. (A) Time-kill assay of ID13, DLP4, and vancomycin (Van) against S. aureus CVCC $546(n=3)$. (B) PAEs of ID13, DLP4, and vancomycin (Van) against S. aureus CVCC $546(n=3)$. (C) Single i.p. treatment with ID13, DLP4, and vancomycin (Van) in the mouse thigh infection model $(n=6)$. Effects of ID13, DLP4, and vancomycin (Van) on inflammatory cytokine levels of (D) TNF- $\alpha$, (E) IL-6, and (F) IL-10. Statistical significance of differences was determined using the two-way ANOVA for (A) and one-way ANOVA for (B-F), followed by Dunnett's multiple comparison. $\left(^{\star}\right)$ indicates the significance between ID13, DLP4, or vancomycin and PBS. ${ }^{\star \star} p<0.01 ;{ }^{\star \star \star} p<0.001 ;{ }^{\star \star \star \star} p<0.0001$.

on the anti-parallel sheet conformation (Merkel and Regan, 1998). Additionally, the net positive charges play an important role in influencing the antibacterial activity of AMPs (Toke, 2005); however, the correlation between peptide charge and bioactivity is complex (Huang et al., 2010). In our study, it showed no linear relationship between the charge and activity of peptides (Table 1); however, it presented a threshold $(+4 \sim+7)$, within which the engineered peptides (ID8 ID26) showed antimicrobial activity. It has been reported that charged residues ( $\mathrm{K}$ or $\mathrm{R}$ ) located at the $\mathrm{T} 1$ (AA from 24 to 27 ) and $\mathrm{T} 2$ 
turns (AA 32 and 33) on the surface of the molecules are particularly important for the activity of insect defensins (Landon et al., 2008); however, in our study, the substitution of K32 in T2 turn with G (ID13) generated a more antimicrobial activity and less toxic molecule. Moreover, amphipathicity is another main parameter responsible for the activity of the engineered peptides (Zelezetsky and Tossi, 2006; Huang et al., 2010). When replacing the hydrophobic AA (A6) of the $\alpha$-helix wheel with the similar but more hydrophobic AA (L or V) which further improves hydrophobicity, the antimicrobial ability of the designed peptides increased compared to the native peptide. Likewise, the mutation $\mathrm{I9L}$ of the $\alpha$-helix wheel with decreased hydrophobicity resulted in a declined antimicrobial ability (Table 1 and Supplementary Figure S2). Studies showed that hydrophobic residues in the $\beta$-sheet replaced by $A$ residue resulted in dramatically decreased biological function of the engineered peptides (Walters et al., 2009; Yang et al., 2009). However, in our study, when the hydrophobic V35 in the $\beta$-sheet was replaced by I residue, the activity of peptide ID30 was not affected. Altogether, the $\operatorname{CS} \alpha \beta$ scaffold is a prerequisite for the activity of the peptide, whereas the activity of the peptides has no linear relationship with charge but increases with the overall hydrophobicity.

The MIC value is a key factor in preliminary screening of candidate peptides, for which $\leq 16 \mu \mathrm{g} / \mathrm{mL}$ or $\leq 16 \mu \mathrm{mol} / \mathrm{L}$ has been posed as a requirement in clinical studies (BarretoSantamaria et al., 2019). In this study, compared with DLP4, ID13 had a lower MIC value $(4 \sim 8 \mu \mathrm{g} / \mathrm{mL})$, hemolytic activity $(0.38 \%)$, and cytotoxicity (71.4\% viability) (Table 2 and Figure 2 ), which may be related to the different $\alpha$-helix content between peptide ID13 and DLP4 in bacterial membrane mimicking (40 mM SDS) and neutral membrane conditions (50\% TFE) (Figure 3; Yang et al., 2019); the higher $\alpha$-helix content of peptides indicates the stronger affinity of peptide to cell membranes and thus more potent activity and toxicity (Barreto-Santamaria et al., 2019). An increase in total hydrophobicity in a certain range also increased the antibacterial activity of ID13 (Table 1). The cell envelope is regarded as the initial contact point of most natural AMPs. Then, AMPs can destroy the cell envelope and effectively induce a leakage of cytosol (Huang et al., 2010). It has been proven in our study that ID13 had the ability to destroy the cell envelope and cause $\mathrm{K}^{+}$or other contents to release extracellularly (Figures 4, 6), and then bound to intracellular target gDNA and destroyed its helical structure (Figure 5), which might result in the inhibition of DNA synthesis (Gottschalk et al., 2015). In contrast, DLP4 showed less potent damage to cell membrane than that of ID13 (Figures 4, 6), but it showed stronger binding ability to $S$. aureus gDNA (Figure 5), which might attribute to its less $\alpha$-helix content in bacterial membrane mimicking conditions and more net positive charges. Other peptides also showed cell membrane damaging abilities to different bacteria (Morgan et al., 2005; Li et al., 2012). The action mode of ID13 and DLP4 is completely different from that of vancomycin which targets the D-Ala-DAla terminus of peptidoglycan to inhibit the cell wall biosynthesis (Wang F. et al., 2018).
Pharmacodynamics has been integral to the design of rational drug dosing regimens (Uckun and Qazi, 2019). Our findings showed that ID13 had excellent bactericidal efficiency, a long PAE, and high efficacy in a mouse thigh infection model against S. aureus CVCC 546 and was superior to DLP4 or vancomycin (Figure 7). Compared with antibiotics, AMPs is less easily to cause bacterial resistance (Moravej et al., 2018b), and it is likely that any changes of bacteria to avoid the AMPs attack are also to grievously influence the proliferation of bacteria (Andersson et al., 2016). All these mean a lower dose and less frequency in administration, thereby potentially reducing treatment costs, drug exposure, and drug resistance. Above all, ID13 presents excellent properties and potency for biomedical applications.

In conclusion, a naturally occurring sequence DLP4 was used as a starting template for rational design of a novel class of "CS $\alpha \beta$ AMPs." Of these peptides, ID13 showed the best antibacterial activity and reduced cytotoxicity and could penetrate and destroy the cell membrane of $S$. aureus CVCC 546, resulting in an increase in $\mathrm{K}^{+}$leakage. After being treated with ID13, perforated, wrinkled, and collapsed S. aureus cells were observed by SEM and TEM. Additionally, ID13 showed potent bactericidal efficiency, a prolonged PAE, and high efficacy in a mouse thigh infection model and was superior to DLP4 or vancomycin. These results suggest that ID13 may be a novel promising antimicrobial candidate to treat infectious diseases caused by $S$. aureus.

\section{DATA AVAILABILITY STATEMENT}

All datasets generated for this study are included in the article/Supplementary Material.

\section{ETHICS STATEMENT}

The animal study was reviewed and approved by the Animal Care and Use Committee of the Feed Research Institute of Chinese Academy of Agricultural Sciences.

\section{AUTHOR CONTRIBUTIONS}

BL, RM, DT, XW, and JW conceived and designed the experiments. BL carried out all the experiments. BL, NY, ZL, and ZW prepared partial materials in the laboratory. DT, XW, $\mathrm{RM}$, and JW contributed to writing. JW contributed to funding acquisition. YH contributed materials and reagents.

\section{FUNDING}

This study was supported by the National Natural Science Foundation of China (Grants 31872393, 31772640, 31702146, 31672456, and 31601968), the AMP Direction of the National Innovation Program of Agricultural Science and Technology in CAAS (Grant CAAS-ASTIP-2013-FRI-02), and its Key Project 
of Alternatives to Antibiotics for Feed Usages (Grant CAAS-ZDXT2018008).

\section{ACKNOWLEDGMENTS}

We acknowledge Tong Zhao from the Core Facility at the Institute of Microbiology at the Chinese Academy of Sciences (CAS) for her technical support with flow cytometer analysis and Jianping Gao from the state Key Laboratory of Biochemical

\section{REFERENCES}

Ahn, H. S., Cho, W., Kang, S. H., Ko, S. S., Park, M. S., Cho, H., et al. (2006). Design and synthesis of novel antimicrobial peptides on the basis of alpha helical domain of Tenecin 1, an insect defensin protein, and structureactivity relationship study. Peptides 27, 640-648. doi: 10.1016/j.peptides.2005. 08.016

Andersson, D. I., Hughes, D., and Kubicek-Sutherland, J. Z. (2016). Mechanisms and consequences of bacterial resistance to antimicrobial peptides. Drug Resist. Update 26, 43-57. doi: 10.1016/j.drup.2016.04.002

Bakshi, K., Liyanage, M. R., Volkin, D. B., and Middaugh, C. R. (2014). Circular dichroism of peptides. Methods Mol. Biol. 1088, 247-253. doi: 10.1007/978-162703-673-3_17

Barreto-Santamaria, A., Patarroyo, M. E., and Curtidor, H. (2019). Designing and optimizing new antimicrobial peptides: all targets are not the same. Crit. Rev. Clin. Lab. Sci. 56, 351-373. doi: 10.1080/10408363.2019.163 1249

Bechinger, B., and Gorr, S. U. (2017). Antimicrobial peptides: mechanisms of action and resistance. J. Dent. Res. 96, 254-260. doi: 10.1177/002203451667 9973

Cerovsky, V., Slaninova, J., Fucik, V., Monincova, L., Bednarova, L., Malon, P., et al. (2011). Lucifensin, a novel insect defensin of medicinal maggots: synthesis and structural study. Chembiochem. 12, 1352-1361. doi: 10.1002/cbic.20110 0066

Chambers, H. F., and Deleo, F. R. (2009). Waves of resistance: Staphylococcus aureus in the antibiotic era. Nat. Rev. Microbiol. 7, 629-641. doi: 10.1038/ nrmicro2200

Cheng, G., Hao, H., Xie, S., Wang, X., Dai, M., Huang, L., et al. (2014). Antibiotic alternatives: the substitution of antibiotics in animal husbandry? Front. Microbiol. 5:217. doi: 10.3389/fmicb.2014.00217

Cheng, W., Chen, H., Su, C., and Yan, S. (2013). Abundance and persistence of antibiotic resistance genes in livestock farms: a comprehensive investigation in eastern China. Environ. Int. 61, 1-7. doi: 10.1016/j.envint.2013. 08.023

Cornet, B., Bonmatin, J. M., and Hetru, C. (1995). Refined three-dimensional solution structure of insect defensin A. Structure 3, 435-448. doi: 10.1016/ s0969-2126(01)00177-0

Coyne, L. A., Latham, S. M., Dawson, S., Donald, I. J., Pearson, R. B., Smith, R. F., et al. (2019). Exploring perspectives on antimicrobial use in livestock: a mixedmethods study of UK pig farmers. Front. Vet. Sci. 6:257. doi: 10.3389/fvets.2019. 00257

Coyne, L. A., Latham, S. M., Williams, N. J., Dawson, S., Donald, I. J., Pearson, R. B., et al. (2016). Understanding the culture of antimicrobial prescribing in agriculture: a qualitative study of UK pig veterinary surgeons. J. Antimicrob. Chemother. 71, 3300-3312. doi: 10.1093/jac/dkw300

da Cunha, N. B., Cobacho, N. B., Viana, J. F. C., Lima, L. A., Sampaio, K. B. O., Dohms, S. S. M., et al. (2017). The next generation of antimicrobial peptides (AMPs) as molecular therapeutic tools for the treatment of diseases with social and economic impacts. Drug Discov. Today 22, 234-248. doi: 10.1016/j.drudis. 2016.10.017

Dan, M., Yehui, W., Qingling, M., Jun, Q., Xingxing, Z., Shuai, M., et al. (2019). Antimicrobial resistance, virulence gene profile and molecular typing of Staphylococcus aureus isolates from dairy cows in Xinjiang province, northwest
Engineering at the Institute of Process Engineering at the Chinese Academy of Sciences (CAS) for his technical support with determination of disulfide bonds.

\section{SUPPLEMENTARY MATERIAL}

The Supplementary Material for this article can be found online at: https://www.frontiersin.org/articles/10.3389/fmicb. 2020.01057/full\#supplementary-material

China. J. Glob. Antimicrob. Resist. 16, 98-104. doi: 10.1016/j.jgar.2018. 08.024

Der Torossian Torres, M., and de la Fuente-Nunez, C. (2019). Reprogramming biological peptides to combat infectious diseases. Chem. Commun. 55, 1502015032. doi: $10.1039 / \mathrm{c} 9 \mathrm{cc} 07898 \mathrm{c}$

Ferber, D. (2002). Antibiotic resistance. Livestock feed ban preserves drugs' power. Science 295, 27-28.

Fjell, C. D., Hiss, J. A., Hancock, R. E., and Schneider, G. (2011). Designing antimicrobial peptides: form follows function. Nat. Rev. Drug Discov. 11, 37-51. doi: $10.1038 / \mathrm{nrd} 3591$

Flamm, R. K., Rhomberg, P. R., Lindley, J. M., Sweeney, K., Ellis-Grosse, E. J., and Shortridge, D. (2019). Evaluation of the bactericidal activity of fosfomycin in combination with selected antimicrobial comparison agents tested against Gram-negative bacterial strains by using time-kill curves. Antimicrob. Agents Chemother. 63:e02549-18. doi: 10.1128/aac.025 49-18

Fluit, A. C. (2012). Livestock-associated Staphylococcus aureus. Clin. Microbiol. Infect. 18, 735-744. doi: 10.1111/j.1469-0691.2012.03846.x

Fojan, P., and Gurevich, L. (2017). Atomic force microscopy study of the interactions of indolicidin with model membranes and DNA. Methods Mol. Biol. 1548, 201-215. doi: 10.1007/978-1-4939-673 7-7_14

Foster, A. P. (2012). Staphylococcal skin disease in livestock. Vet. Dermatol. 23, 342-351. doi: 10.1111/j.1365-3164.2012.01093.x

Gottschalk, S., Gottlieb, C. T., Vestergaard, M., Hansen, P. R., Gram, L., Ingmer, H., et al. (2015). Amphibian antimicrobial peptide fallaxin analogue FL9 affects virulence gene expression and DNA replication in Staphylococcus aureus. J. Med. Microbiol. 64, 1504-1513. doi: 10.1099/jmm.0.00 0177

Hiramatsu, K. (2001). Vancomycin-resistant Staphylococcus aureus : a new model of antibiotic resistance. Lancet Infect. Dis. 1, 147-155. doi: 10.1016/s14733099(01)00091-3

Huang, Y. B., Huang, J. F., and Chen, Y. X. (2010). Alpha-helical cationic antimicrobial peptides: relationships of structure and function. Protein Cell 1, 143-152. doi: 10.1007/s13238-010-0004-3

Józefiak, A., and Engberg, R. (2017). Insect proteins as a potential source of antimicrobial peptides in livestock production. A review. J. Anim. Feed Sci. 26, 87-99. doi: 10.22358/jafs/69998/2017

Kang, H. K., Kim, C., Seo, C. H., and Park, Y. (2017). The therapeutic applications of antimicrobial peptides (AMPs): a patent review. J. Microbiol. 55, 1-12. doi: 10.1007/s12275-017-6452-1

Koehbach, J. (2017). Structure-activity relationships of insect defensins. Front. Chem. 5:45. doi: 10.3389/fchem.2017.00045

Kollef, M. H. (2007). Limitations of vancomycin in the management of resistant Staphylococcal infections. Clin. Infect. Dis. 45(Suppl. 3), S191-S195. doi: 10. 1086/519470

Kubicek-Sutherland, J. Z., Lofton, H., Vestergaard, M., Hjort, K., Ingmer, H., and Andersson, D. I. (2017). Antimicrobial peptide exposure selects for Staphylococcus aureus resistance to human defence peptides. J. Antimicrob. Chemother. 72, 115-127. doi: 10.1093/jac/dkw381

Lai, C. C., Lee, C. M., Chiang, H. T., Lu, M. C., Wang, L. F., Tsai, T. L., et al. (2018). Methicillin-resistant Staphylococcus aureus sequence type 45 with high rates of ciprofloxacin and tetracycline resistance in the residents and environments of 
long-term care facilities in Taiwan. J. Infect. 76, 305-307. doi: 10.1016/j.jinf. 2017.11.003

Lammie, S. L., and Hughes, J. M. (2016). Antimicrobial resistance, food safety, and one health: the need for convergence. Annu. Rev. Food Sci. 7, 287-312. doi: 10.1146/annurev-food-041715-033251

Landon, C., Barbault, F., Legrain, M., Guenneugues, M., and Vovelle, F. (2008). Rational design of peptides active against the gram positive bacteria Staphylococcus aureus. Proteins 72, 229-239. doi: 10.1002/prot.21912

Laxminarayan, R., Duse, A., Wattal, C., Zaidi, A. K. M., Wertheim, H. F. L., Sumpradit, N., et al. (2013). Antibiotic resistance-the need for global solutions. Lancet Infect. Dis. 13, 1057-1098. doi: 10.1016/s1473-3099(13)70318-9

Lee, J., Lee, D., Choi, H., Kim, H. H., Kim, H., Hwang, J. S., et al. (2014). Structureactivity relationships of the intramolecular disulfide bonds in coprisin, a defensin from the dung beetle. BMB Rep. 47, 625-630. doi: 10.5483/bmbrep. 2014.47.11.262

Lee, K. H., Hong, S. Y., and Oh, J. E. (1998). Synthesis and structure-function study about tenecin 1, an antibacterial protein from larvae of Tenebrio molitor. FEBS Lett. 439, 41-45. doi: 10.1016/s0014-5793(98)01333-7

Li, L., Shi, Y., Su, G., and Le, G. (2012). Selectivity for and destruction of Salmonella typhimurium via a membrane damage mechanism of a cell-penetrating peptide ppTG20 analogue. Int. J. Antimicrob. Agents 40, 337-343. doi: 10.1016/j. ijantimicag.2012.05.026

Li, Z., Mao, R., Teng, D., Hao, Y., Chen, H., Wang, X., et al. (2017). Antibacterial and immunomodulatory activities of insect defensins-DLP2 and DLP4 against multidrug-resistant Staphylococcus aureus. Sci. Rep. 7:12124. doi: 10.1038/ s41598-017-10839-4

Lin, X., Liu, Y., Deng, J., Lyu, Y., Qian, P., Li, Y., et al. (2018). Multiple advanced logic gates made of DNA-Ag nanocluster and the application for intelligent detection of pathogenic bacterial genes. Chem. Sci. 9, 1774-1781. doi: 10.1039/ c7sc05246d

Ling, L. L., Schneider, T., Peoples, A. J., Spoering, A. L., Engels, I., Conlon, B. P., et al. (2015). A new antibiotic kills pathogens without detectable resistance. Nature 517, 455-459. doi: 10.1038/nature14098

Maertens, H., De Reu, K., Meyer, E., Van Coillie, E., and Dewulf, J. (2019). Limited association between disinfectant use and either antibiotic or disinfectant susceptibility of Escherichia coli in both poultry and pig husbandry. BMC Vet. Res. 15:310. doi: 10.1186/s12917-019-2044-0

Merkel, J. S., and Regan, L. (1998). Aromatic rescue of glycine in $\beta$ sheets. Fold Des. 3, 449-456. doi: 10.1016/S1359-0278(98)00062-5

Miao, J., Zhou, J., Liu, G., Chen, F., Chen, Y., Gao, X., et al. (2016). Membrane disruption and DNA binding of Staphylococcus aureus cell induced by a novel antimicrobial peptide produced by Lactobacillus paracasei subsp. tolerans FX-6. Food Control 59, 609-613. doi: 10.1016/j.foodcont.2015.06.044

Moravej, H., Fasihi-Ramandi, M., Moghaddam, M. M., and Mirnejad, R. (2018a). Cytotoxicity and antibacterial effect of Trp-substituted $\mathrm{cm} 11$ cationic peptide against drug-resistant isolates of brucella melitensis alone and in combination with recommended antibiotics. Int. J. Pept. Res. Ther. 25, 235-245. doi: 10.1007/ s10989-017-9658-5

Moravej, H., Moravej, Z., Yazdanparast, M., Heiat, M., Mirhosseini, A., Moosazadeh Moghaddam, M., et al. (2018b). Antimicrobial peptides: features, action, and their resistance mechanisms in bacteria. Microb. Drug Resist. 24, 747-767. doi: 10.1089/mdr.2017.0392

Morgan, S. M., O'connor, P. M., Cotter, P. D., Ross, R. P., and Hill, C. (2005). Sequential actions of the two component peptides of the lantibiotic lacticin 3147 explain its antimicrobial activity at nanomolar concentrations. Antimicrob. Agents Chemother. 49, 2606-2611. doi: 10.1128/AAC.49.7.2606-2611.2005

Oh, J. T., Cassino, C., and Schuch, R. (2019). Postantibiotic and sub-mic effects of exebacase (lysin CF-301) enhance antimicrobial activity against Staphylococcus aureus. Antimicrob. Agents Chemother. 63:e02616-18. doi: 10.1128/aac.026 16-18

Park, S. I., Kim, J. W., and Yoe, S. M. (2015). Purification and characterization of a novel antibacterial peptide from black soldier fly (Hermetia illucens) larvae. Dev. Comp. Immunol. 52, 98-106. doi: 10.1016/j.dci.2015.04.018

Pirolo, M., Gioffre, A., Visaggio, D., Gherardi, M., Pavia, G., Samele, P., et al. (2019). Prevalence, molecular epidemiology, and antimicrobial resistance of methicillin-resistant Staphylococcus aureus from swine in southern Italy. BMC Microbiol. 19:51. doi: 10.1186/s12866-019-1422-x
Roncevic, T., Puizina, J., and Tossi, A. (2019). Antimicrobial peptides as antiinfective agents in pre-post-antibiotic Era? Int. J. Mol. Sci. 20:E5713. doi: 10. 3390/ijms20225713

Sakoulas, G., Moise-Broder, P. A., Schentag, J., Forrest, A., and Moellering, R. C. (2004). Relationship of MIC and bactericidal activity to efficacy of vancomycin for treatment of methicillin-resistant Staphylococcus aureus bacteremia. J. Clin. Microbiol. 42, 2398-2402. doi: 10.1128/JCM.42.6.2398-2402. 2004

Tan, P., Lai, Z., Zhu, Y., Shao, C., Akhtar, M. U., Li, W., et al. (2019). Multiple strategy optimization of specifically targeted antimicrobial peptide based on structure-activity relationships to enhance bactericidal efficiency. ACS Biomat. Sci. Eng. 6, 398-414. doi: 10.1021/acsbiomaterials.9b00937

Toke, O. (2005). Antimicrobial peptides: new candidates in the fight against bacterial infections. Biopolymers 80, 717-735. doi: 10.1002/bip.20286

Uckun, F. M., and Qazi, S. (2019). "Role of clinical pharmacodynamics studies in the era of precision medicines against cancer," in Drug Discovery and Evaluation: Methods in Clinical Pharmacology, eds H. G. Vogel, J. Maas, and A. Gebauer (Cham: Springer).

Van Boeckel, T. P., Brower, C., Gilbert, M., Grenfell, B. T., Levin, S. A., Robinson, T. P., et al. (2015). Global trends in antimicrobial use in food animals. Proc. Natl. Acad. Sci. U.S.A. 112, 5649-5654. doi: 10.1073/pnas.1503141112

Walters, D. E., Cragin, T., Jin, Z., Rumbley, J. N., and Hellekant, G. (2009). Design and evaluation of new analogs of the sweet protein brazzein. Chem. Senses. 34, 679-683. doi: 10.1093/chemse/bjp048

Wang, F., Zhou, H., Olademehin, O. P., Kim, S. J., and Tao, P. (2018). Insights into key interactions between vancomycin and bacterial cell wall structures. ACS Omega 3, 37-45. doi: 10.1021/acsomega.7b01483

Wang, X., Wang, X., Teng, D., Mao, R., Hao, Y., Yang, N., et al. (2018). Increased intracellular activity of MP1102 and NZ2114 against Staphylococcus aureus in vitro and in vivo. Sci. Rep. 8:4204. doi: 10.1038/s41598-018-22245-5

Wang, S., Zeng, X., Yang, Q., and Qiao, S. (2016). Antimicrobial peptides as potential alternatives to antibiotics in food animal industry. Int. J Mol. Sci. 17:603. doi: 10.3390/ijms17050603

Wenzel, M., Chiriac, A. I., Otto, A., Zweytick, D., May, C., Schumacher, C., et al. (2014). Small cationic antimicrobial peptides delocalize peripheral membrane proteins. Proc. Natl. Acad. Sci. U.S.A. 111, E1409-E1418. doi: 10.1073/pnas. 1319900111

Wiegand, I., Hilpert, K., and Hancock, R. E. W. (2008). Agar and broth dilution methods to determine the minimal inhibitory concentration (MIC) of antimicrobial substances. Nat. Protoc. 3, 163-175. doi: 10.1038/nprot.2007.521

Yang, N., Teng, D., Mao, R., Hao, Y., Wang, X., Wang, Z., et al. (2019). A recombinant fungal defensin-like peptide-P2 combats multidrug-resistant Staphylococcus aureus and biofilms. Appl. Microbiol. Biotechnol. 103, 51935213. doi: 10.1007/s00253-019-09785-0

Yang, Y. F., Cheng, K. C., Tsai, P. H., Liu, C. C., Lee, T. R., and Lyu, P. C. (2009). Alanine substitutions of noncysteine residues in the cysteine-stabilized $\alpha \beta$ motif. Protein Sci. 18, 1498-1506. doi: 10.1002/pro.164

Yao, H., Wynendaele, E., Xu, X., Kosgei, A., and De Spiegeleer, B. (2018). Circular dichroism in functional quality evaluation of medicines. J. Pharm. Biomed. Anal. 147, 50-64. doi: 10.1016/j.jpba.2017.08.031

Yi, H. Y., Chowdhury, M., Huang, Y. D., and Yu, X. Q. (2014). Insect antimicrobial peptides and their applications. Appl. Microbiol. Biotechnol. 98, 5807-5822. doi: 10.1007/s00253-014-5792-6

Zelezetsky, I., and Tossi, A. (2006). Alpha-helical antimicrobial peptides-using a sequence template to guide structure-activity relationship studies. Biochim. Biophys. Acta 1758, 1436-1449. doi: 10.1016/j.bbamem.2006.03.021

Zhanel, G. G., and Craig, W. A. (1994). Pharmacokinetic contributions to postantibiotic effects. Focus on aminoglycosides. Clin. Pharmacokinet. 27, 377392. doi: 10.2165/00003088-199427050-00005

Zhang, L. J., and Gallo, R. L. (2016). Antimicrobial peptides. Curr. Biol. 26, R14-R19. doi: 10.1016/j.cub.2015.11.017

Zhang, Y., Teng, D., Mao, R., Wang, X., Xi, D., Hu, X., et al. (2014). High expression of a plectasin-derived peptide NZ2114 in Pichia pastoris and its pharmacodynamics, postantibiotic and synergy against Staphylococcus aureus. Appl. Microbiol. Biotechnol. 98, 681-694. doi: 10.1007/s00253-013-4881-2

Zhang, Y., Teng, D., Wang, X., Mao, R., Cao, X., Hu, X., et al. (2015). In vitro and in vivo characterization of a new recombinant antimicrobial peptide, MP1102, 
against methicillin-resistant Staphylococcus aureus. Appl. Microbiol. Biotechnol. 99, 6255-6266. doi: 10.1007/s00253-015-6394-7

Zhao, F., Yang, N., Wang, X., Mao, R., Hao, Y., Li, Z., et al. (2019). In vitro/vivo mechanism of action of MP1102 with low/nonresistance against Streptococcus suis type 2 strain CVCC 3928. Front. Cell Infect. Microbiol. 9:48. doi: 10.3389/ fcimb.2019.00048

Zhu, X., Liu, D., Singh, A. K., Drolia, R., Bai, X., Tenguria, S., et al. (2018). Tunicamycin mediated inhibition of wall teichoic acid affects Staphylococcus aureus and Listeria monocytogenes cell morphology, biofilm formation and virulence. Front. Microbiol. 9:1352. doi: 10.3389/fmicb.2018. 01352
Conflict of Interest: The authors declare that the research was conducted in the absence of any commercial or financial relationships that could be construed as a potential conflict of interest.

Copyright (๑) 2020 Li, Yang, Wang, Hao, Mao, Li, Wang, Teng and Wang. This is an open-access article distributed under the terms of the Creative Commons Attribution License (CC BY). The use, distribution or reproduction in other forums is permitted, provided the original author(s) and the copyright owner(s) are credited and that the original publication in this journal is cited, in accordance with accepted academic practice. No use, distribution or reproduction is permitted which does not comply with these terms. 